\title{
Among family variation in survival and gene expression uncovers adaptive genetic variation in a threatened fish
}

Avril M. Harder ${ }^{*}$, Janna R. Willoughby ${ }^{2,3}$, William R. Ardren ${ }^{4}$, Mark R. Christie ${ }^{1,2}$

1. Department of Biological Sciences, Purdue University, 915 W. State St., West Lafayette, IN 47907, USA

2. Department of Forestry and Natural Resources, Purdue University, 715 W. State St., West

Lafayette, IN 47907, USA

3. School of Forestry and Wildlife Sciences, Auburn University, 602 Duncan Dr., Auburn, AL 36849, USA

4. U. S. Fish and Wildlife Service, Western New England Complex, 11 Lincoln St., Essex Junction, VT 05452, USA

*corresponding author 


\section{Abstract}

2 Variation in among-family transcriptional responses to different environmental conditions can

3 help to identify adaptive genetic variation, even prior to a selective event. Coupling differential

4 gene expression with formal survival analyses allows for the disentanglement of treatment

5 effects, required for understanding how individuals plastically respond to environmental

6 stressors, from the adaptive genetic variation responsible for among-family variation in survival

7 and gene expression. We applied this experimental design to investigate responses to an

8 emerging conservation issue, thiamine (vitamin $\mathrm{B}_{1}$ ) deficiency, in a threatened population of

9 Atlantic salmon (Salmo salar). Thiamine is an essential vitamin that is increasingly limited in many ecosystems. In Lake Champlain, Atlantic salmon cannot acquire thiamine in sufficient

11 quantities to support natural reproduction; fertilized eggs must be reared in hatcheries and treated

12 with supplemental thiamine. We evaluated transcriptional responses (RNA-seq) to thiamine

13 treatment across families and found 3,616 genes differentially expressed between control (no

14 supplemental thiamine) and treatment individuals. Fewer genes changed expression additively

15 (i.e., equally among families) than non-additively (i.e., family-by-treatment effects) in response

16 to thiamine. Differentially expressed genes were related to known physiological effects of

17 thiamine deficiency, including oxidative stress, cardiovascular irregularities, and neurological

18 abnormalities. We also identified 1,446 putatively adaptive genes that were strongly associated

19 with among-family survival in the absence of thiamine treatment, many of which related to

20 neurogenesis and visual perception. Our results highlight the utility of coupling RNA-seq with

21 formal survival analyses to identify candidate genes that underlie the among-family variation in

22 survival required for an adaptive response to natural selection.

23 Keywords: Atlantic salmon, contemporary evolution, RNA-seq, thiamine, transcriptomics 


\section{Introduction}

25 Understanding if and how species can adapt to rapidly changing environmental conditions is a

26 primary goal of modern conservation biology (Bernatchez, 2016; Stockwell, Hendry, \&

27 Kinnison, 2003). One of the key challenges in meeting this goal is uncovering the adaptive

28 genetic variation required for a response to selection and deciphering whether this adaptive

29 genetic variation will be sufficient to respond to anthropogenically-induced agents of selection.

30 Contemporary genomic approaches have revolutionized our ability to identify regions of the

31 genome responding to selection, even over relatively short time periods (Franks, Kane, O’Hara,

32 Tittes, \& Rest, 2016; van't Hof et al., 2016; Willoughby, Harder, Tennessen, Scribner, \&

33 Christie, 2018). However, such methods often lack sufficient power to detect rapid responses to

34 selection, especially when examining polygenic traits shaped by large numbers of loci of small

35 effect (Pritchard, Pickrell, \& Coop, 2010; Wellenreuther \& Hansson, 2016). Furthermore,

36 genomic approaches can only provide insights after selection has already occurred; thus their

37 utility for predicting responses to selection requires appropriate study systems or long-term

38 experimental breeding designs. One alternative to these approaches is experimental

39 transcriptomics. By carefully designing treatments, rearing F1 offspring in a common

40 environment, and deeply sequencing mRNA, it is possible to uncover an adaptive, genetic

41 response to selection (Christie, Marine, Fox, French, \& Blouin, 2016; Passow et al., 2017; Uusi-

42 Heikkilä, Sävilammi, Leder, Arlinghaus, \& Primmer, 2017). Coupling family-level replication

43 and formal survival analyses allows for the disentanglement of treatment effects, required for

44 understanding how individuals plastically respond to environmental stressors, and among-family

45 variation in survival and gene expression. Here, we apply these techniques to a threatened fish 
46 population, whose successful reintroduction will require an adaptive response to an emerging

47 conservation issue, thiamine deficiency.

Evidence is mounting that populations of diverse taxa are becoming increasingly

49 deficient in thiamine (vitamin $\mathrm{B}_{1}$ ) (Balk et al., 2009, 2016). For example, high rates of mortality

50 or reduced reproductive success associated with thiamine deficiency have been observed in

51 invertebrates (Balk et al., 2016), fishes (Futia et al., 2017), reptiles (Honeyfield et al., 2008; Ross

52 et al., 2009), and birds (Balk et al., 2009). Furthermore, many cases of thiamine deficiency

53 remain undetected. From a conservation standpoint, it is particularly concerning that thiamine

54 deficiency remains largely undetected despite potentially being a large driver of population

55 declines.

Thiamine is an essential vitamin that is synthesized by prokaryotes, plants, and fungi;

57 animals are incapable of producing thiamine and primarily acquire the vitamin through their

58 diets (Bettendorff, 2013). The physiological manifestations of thiamine deficiency are directly

59 related to thiamine's roles in bioenergetic, neurological, and cardiovascular pathways. Thiamine

60 serves as a cofactor for enzymes in metabolism and energy production pathways (i.e., pentose

61 phosphate pathway and tricarboxylic acid cycle) and thiamine deficiency leads to extreme

62 lethargy (Brown et al., 2005; Fitzsimons, Brown, Honeyfield, \& Hnath, 1999). Thiamine is also

63 required for production of neurotransmitters, antioxidants, and myelin (Bettendorff, 2013),

64 consistent with the neurological and behavioral signs of thiamine deficiency, including brain

65 lesions (Butterworth, 2009; Honeyfield et al., 2008; Lee, Jaroszewska, Dabrowski, Czesny, \&

66 Rinchard, 2009) and uncoordinated movements (Brown et al., 2005; Fisher, Spitzbergen, et al.,

67 1995; Fitzsimons et al., 2005; Sechi \& Serra, 2007). Thiamine deficiency can also impair

68 cardiovascular function, leading to low blood pressure, irregular heart rate, pulmonary edema, 
and circulatory collapse (Essa et al., 2011; Sechi \& Serra, 2007). Because thiamine plays a central role in growth, development, and proper neurological function (Bettendorff, 2013),

71 thiamine deficiency can impair an individual's capacity to forage, avoid predation, and reproduce

72 (Carvalho et al., 2009; Fisher, Spitzbergen, et al., 1995; Fitzsimons et al., 2009), all of which can

73 contribute to large reductions in population size (Ketola, Bowser, Wooster, Wedge, \& Hurst,

74 2000; Mörner et al., 2017).

The underlying causes of thiamine deficiency vary among taxa and environments. In

76 fishes, the emergence of thiamine deficiency is largely attributed to diet. For example, thiamine

77 deficiency has often been observed in salmonids with diets containing alewife (Alosa

78 pseudoharengus) and rainbow smelt (Osmerus mordax), both of which contain high levels of

79 thiaminase, a thiamine-degrading enzyme (reviewed in Harder et al., 2018). In the Baltic Sea, the occurrence of thiamine deficiency in Atlantic salmon (Salmo salar) also coincides with the

81 consumption of fishes with low thiamine:fat content ratios, including Atlantic herring (Clupea

82 harengus) and sprat (Sprattus sprattus) (Hansson et al., 2001; Keinänen et al., 2012). However,

83 these fishes also contain thiaminase, making it difficult to establish low thiamine:fat content

84 ratios as direct, causative agents of thiamine deficiency. For adult salmon returning to spawn, the

85 most obvious signs of thiamine deficiency are uncoordinated, "wiggling" swimming patterns and

86 an inability to remain upright in the water column (Fisher, Spitsbergen, Iamonte, Little, \&

87 Delonay, 1995; Fitzsimons et al., 2005). If thiamine deficient individuals are able to spawn, these

88 behaviors are inevitably mirrored in their offspring. Individuals hatching from thiamine deficient

89 eggs do not survive for more than a few weeks and exhibit physical signs of deficiency, such as

90 hemorrhaging and large yolk sacs with opacities and edema, prior to death (Fig. 1A) (Fisher,

91 Spitsbergen, et al., 1995). The inability of thiamine deficient salmon to successfully reproduce is 
92 an emerging conservation and management issue (reviewed in Harder et al., 2018), and impedes

93 reintroduction efforts throughout their native range.

95 Atlantic salmon were extirpated from the lake in the early 1800s (Marsden \& Langdon, 2012; SI

96 Introduction). Diversifying the forage base or controlling the alewife population in Lake

97 Champlain could alleviate thiamine deficiency in Atlantic salmon, but efforts to eradicate

98 invasive species after population establishment are often prohibitively expensive and the

99 possibility of reinvasion cannot be eliminated (Myers, Simberloff, Kuris, \& Carey, 2000).

100 Alternatively, recent research suggests that Atlantic salmon populations with diets high in

101 thiaminase may have genetically adapted to low thiamine availability (Houde, Saez, Wilson,

102 Bureau, \& Neff, 2015). This rapid genetic adaptation could be the result of selection on genes

103 associated with thiamine-dependent pathways. For example, conformational changes in enzymes

104 requiring thiamine as a cofactor could increase the binding affinity for thiamine or, alternatively,

105 variation in regulatory sequences could modify the expression of genes involved in thiamine

106 uptake and intracellular transport. However, the application of supplemental thiamine to all

107 fertilized eggs reared in the Lake Champlain hatchery precludes selection related to thiamine

108 deficiency at early life stages, and it is currently unknown whether genetic variation in this

109 population could support a response to such selection. By coupling thiamine treatments, RNA-

110 seq, and survival analyses on F1 offspring from 9 families raised in a common environment, we

111 identified an among-family adaptive response in a thiamine-deficient population of Atlantic

112 salmon and identified pathways and functions impacted by thiamine deficiency. Categorizing

113 relationships between gene expression and survivorship patterns revealed two distinct groups of

114 differentially expressed genes that (1) underlie putatively adaptive responses to thiamine 
115 deficiency among families and (2) reflect the treatment effect of thiamine use regardless of 116 genetic differences. Our results are consistent with a heritable, among-family basis for tolerance

117 to low thiamine availability.

\section{Methods}

119 Study system and experimental crosses

120 We collected gametes from 35 pairs of adult male and female Atlantic salmon returning to the Ed

121 Weed Fish Culture Station (Grand Isle, Vermont, USA) across two spawning seasons: 17 pairs in

122 November 2016 and 18 pairs in November 2017. We immediately froze approximately 50 eggs

123 from each female on dry ice for total thiamine concentration analysis whereby two, 1-g

124 biological replicates of unfertilized egg tissue were analyzed via high performance liquid

125 chromatography (sensu stricto Futia et al. 2017). We also performed total thiamine concentration

126 analyses on 2-g samples of maternal muscle tissue sampled from each female (two samples per

127 female) during U.S. Fish and Wildlife Service disease testing procedures. We transported

128 gametes at $4{ }^{\circ} \mathrm{C}$ to the White River National Fish Hatchery (Bethel, Vermont, USA), where we

129 systematically combined milt and eggs to generate 35 families (see SI Methods for crossing

130 details). We divided fertilized eggs from each family into two groups, placing one group into a

$1311 \%$ thiamine mononitrate solution (hereafter, "treated") and the other into a control water bath

132 (hereafter, "untreated"). After 30 minutes, we rinsed all eggs with fresh water and transferred

133 them to heath trays with one tray per family and treatment combination. We left the eggs

134 undisturbed until reaching the eyed stage (when individuals exhibit retinal pigmentation,

135 approximately 50 days post fertilization), at which point we counted and removed inviable eggs.

136 After the eyed stage was reached, we recorded mortality and removed inviable eggs from all

137 trays each week. Hatching occurred approximately 75 days post fertilization and we continued to 
138 monitor and remove dead individuals from all trays each week for the remainder of the

139 experiments. We concluded the experiments after surviving fry had absorbed their yolk sacs

140 ( 130 days post fertilization) and just prior to initiation of exogenous feeding.

141 Sampling for RNA-seq

142 At 95 days post fertilization, we sampled a total of thirty-six individuals for gene expression

143 analyses from 9 of the 18 families spawned in 2017. Due to hatchery broodstock quotas for

144 treated individuals, we were limited to sampling these 9 families. To control for variation in

145 development, we only sampled from families that were spawned on the same day. We froze

146 individuals from each family and treatment group in dry cryogenic shipping dewars charged with

147 liquid nitrogen and shipped them to Purdue University for storage at $-80{ }^{\circ} \mathrm{C}$. We subsequently

148 placed two frozen individuals from each family and treatment group $(n=9$ families * 2

149 treatments $(+/-$ supplemental thiamine $) * 2$ individuals $=36)$ into 10 volumes of RNAlater-ICE

150 (Invitrogen) pre-chilled to $-80{ }^{\circ} \mathrm{C}$ and allowed the samples to reach $-20{ }^{\circ} \mathrm{C}$ overnight. We then

151 homogenized samples using a TissueRuptor II (Qiagen) and extracted total RNA from each

152 homogenate using an RNeasy kit (Qiagen).

153 Survival analyses

154 We generated a dose-response curve for egg thiamine concentration and proportion of untreated

155 individuals in each family surviving at the end of the experiments with the $\operatorname{drc}$ package (Ritz,

156 Baty, Streibig, \& Gerhard, 2015) in R version 3.5.3 (R Core Team, 2019). We selected the

157 appropriate model by using the mselect function to calculate AIC values, with the two-parameter

158 log-logistic function having the lowest AIC value. We next calculated effective concentrations of 
egg thiamine required for $25 \%$ and $50 \%$ survival ( $\mathrm{EC}_{25}$ and $\mathrm{EC}_{50}$, respectively) from the resulting logistic curve.

For the 9 families used in RNA-seq, we conducted survival analyses to determine whether treatment affected survival within a family over time and to determine the relative risks of death associated with belonging to each family according to survivorship of untreated individuals. We constructed Kaplan-Meier survival distributions for each family and treatment combination and used a log-rank test to determine whether treatment status significantly affected survival within each family (Kleinbaum \& Klein, 2012). We then compared survival distributions for untreated individuals from each family against the survival distribution for untreated individuals from family A (the family with the highest survival rate of all families). We used Cox proportional hazards regressions to calculate hazard ratio values for all families (Cox, 1972) using the survival package (Therneau, 2015) in R. We censored individuals removed for RNA-seq in the analysis. For each family, the calculated hazard ratio represents the probability of mortality associated with belonging to that family, compared to family A. We also conducted a linear regression to test for a relationship between hazard ratio value and egg thiamine concentration. To meet assumptions of normality, we log-transformed hazard ratio values prior to all regression analyses.

When spawning families for this study, reciprocal crosses were not feasible due to limited egg and milt availability, therefore, we could not formally test for maternal effects (sensu Christie et al., 2016). However, female size is often correlated with offspring size, and larger offspring frequently exhibit higher fitness than smaller offspring in a common environment (reviewed in Marshall, Heppell, Munch, \& Warner, 2010). We therefore performed linear regressions to test for relationships between maternal physical characteristics (i.e., standard 
182 length and weight) and proportion of untreated offspring surviving at the end of the experiment.

183 We also plotted maternal muscle and egg thiamine concentration against proportion of untreated

184 offspring surviving for the 9 families sampled for RNA-seq. A strong association between

185 maternal characteristics and untreated offspring survival might indicate that maternal condition

186 plays a larger role in determining thiamine deficiency outcomes than among-family genetic

187 variation.

RNA-seq and sequence processing

189 We assessed total RNA concentration and quality on an Agilent BioAnalyzer at the Purdue

190 Genomics Core Facility, with sample RIN scores ranging from 9.3-10.0. One library was

191 prepared for each individual using the TruSeq Stranded mRNA protocol (Illumina) and cDNA

192 was sequenced on an Illumina NovaSeq 6000 to generate an average of 87 million 150 bp paired-

193 end reads per library (Table S1). We removed adapter sequences and clipped poor quality bases

194 (quality score < 20) from both ends of reads using Trimmomatic (Bolger, Lohse, \& Usadel,

195 2014) and aligned reads to the annotated Atlantic salmon reference genome (S. salar

196 ICSASG_v2 assembly, NCBI accession GCA_000233375.4; Lien et al., 2016) using HISAT2

197 (Kim, Langmead, \& Salzberg, 2015) with the --downstream-transcriptome-assembly option and

198 reporting primary alignments. We next assembled transcripts for each sample using StringTie

199 (Pertea et al., 2015) default parameters and the Atlantic salmon reference annotation file

200 (ICSASG_v2) to guide assembly, and merged sample transcripts using StringTie. A transcript

201 count matrix was next created with featureCounts (Liao, Smyth, \& Shi, 2014), excluding

202 chimeric fragments (-C option) and requiring that both reads in a pair be successfully mapped (-

$203 B$ option). By default, featureCounts does not count reads with multiple alignments (i.e., a single 
204 read aligned to multiple locations in the reference) or read pairs that overlap multiple features,

205 and we retained these settings in our analyses.

206

207

208

209

210

211

212

213

214

215

216

217

218

219

220

221

222

223

224

225

\section{Differential expression analyses: treatment effects}

We first made comparisons between treated and untreated individuals using both an a priori list of reference genes and a standard discovery-based gene identification pipeline. We generated a

list of a priori genes predicted to be differentially expressed between treated and untreated samples using 4 criteria: (1) genes associated with thiamine-related biological process gene ontology (GO) terms (any line containing "thiamine” in Ssal_ICSASG_v2_GOAccession.txt downloaded from SalmoBase (Samy et al., 2017) on June 28, 2018), (2) genes encoding thiamine diphosphate (TDP) dependent enzymes, (3) genes encoding enzymes that contain a TDP binding site (NCBI conserved protein domain family "TPP_enzymes”), and (4) genes included in the $S$. salar thiamine metabolism pathway in the NCBI BioSystems Database (BSID: 1429556).

We conducted differential gene expression analyses separately in DESeq2 (Love, Huber, \& Anders, 2014) for: 1 . the a priori list of predicted differentially expressed genes (DEGs) and 2. the list of all assembled transcripts. We identified DEGs associated with thiamine treatment status while controlling for the effects of family, and considered genes with an FDR-adjusted $p$ value $\left(p_{\text {adj }}\right)<0.05$ to be differentially expressed. We used the prcomp command in $\mathrm{R}$ to conduct a principal component analysis for DEGs identified from the list of all assembled transcripts.

Using the count matrix for all samples, we identified modules of co-expressed genes by calculating pair-wise Pearson correlations between each pair of genes using the WGCNA package (Langfelder \& Horvath, 2008). We set the minimum modules size to 30 genes and merged correlated modules $\left(r^{2}>0.9\right)$. Each module comprised genes that showed similar 
expression patterns across samples within a treatment. Following the approach outlined in

227 Langfelder and Horvath (2008) we performed the following steps. First, we summarized module

228 expression using a principal components analysis (PCA) and calculated eigengenes as the first

229 principal component (PC1) for each module. Second, we used the Pearson correlation to search

230 for associations between module eigengenes and treatment status, and calculated $p$-values for

231 correlations using a Student's asymptotic test. Finally, we applied a Bonferroni correction to

232 account for multiple testing.

For each module significantly associated with treatment status, we performed a gene

234 ontology (GO) enrichment analysis to identify which Biological Process GO terms associated

235 with the DEGs were overrepresented compared to the genome-wide complement of S. salar GO

236 terms $(p<0.001)$. We used the TopGo package in $\mathrm{R}$ (Alexa \& Rahnenfuhrer, 2016), which is

237 less biased towards the most general GO terms because it employs a hierarchical methodology,

238 and chose the 'weight01' algorithm because this method efficiently identifies enriched terms at

239 all levels of the GO hierarchy while limiting the proportion of false positives (Alexa,

240 Rahnenfuhrer, \& Lengauer, 2006). After identifying overrepresented GO terms in each module,

241 we created a list of terms unique to each module (all overrepresented terms shared among all 3

242 modules are provided in Table S2). For each module, we created a list of the top 20 genes ranked

243 by gene significance (a value calculated in WGCNA that indicates the biological significance of

244 a module gene with respect to the explanatory variable of interest). We used unique GO terms

245 associated with the top 20 genes to construct a network of GO terms for each module, and the

246 metacoder package (Foster, Sharpton, \& Grünwald, 2017) to visualize networks in R. We pruned

247 internal nodes from each network for ease of visualization. 
Identifying putatively adaptive genes

249 To identify putatively adaptive genes that could respond to selection imposed by thiamine

250 deficiency, we generated a transcript count matrix for untreated individuals only. We conducted

251 differential gene expression analysis on this group in DESeq2 in R with family hazard ratio value

252 as the explanatory variable. We considered genes with $p_{\text {adj }}<0.05$ and with a fold-change $>1$

253 ( $\log _{2}$ fold-change $>0.5$ between the families with the lowest and highest hazard ratio values) to

254 be putatively adaptive.

We further categorized the adaptively expressed genes by whether increasing hazard ratio

256 (i.e., increasing probability of mortality) was associated with either an increase or a decrease in

257 gene expression, when analyzed across families. We further filtered genes belonging to each

258 category by applying a linear regression approach to each gene, with $\log ($ hazard ratio) as the

259 explanatory variable and overall gene expression (fragments per million mapped fragments,

260 FPM) as the response variable. To account for the fact that we sequenced two siblings from each

261 family, we conducted each regression using 1 randomly selected individual from each family,

262 and repeated this process 1,000 times per gene. We calculated coefficient means for each gene

263 and variances in the means as $95 \%$ confidence intervals. We discarded genes from further

264 analyses if the slope of the regression did not differ from 0 or if the adjusted $\mathrm{r}^{2}$ of the regression

265 was $<0.3$. For each group of putatively adaptive genes, we performed a gene ontology (GO)

266 enrichment analysis using the same approach described above. We ranked GO terms by $p$-value

267 for each category and retained the top 50 terms from each group $(p<0.001$ for all retained 268 terms). 
270 To categorize treatment effects, we first limited our analyses to genes previously identified as

271 differentially expressed with respect to thiamine treatment (see "Differential expression analyses:

272 treatment effects" section above). Additive effects occur when the response to the thiamine

273 treatment was equal across families. When the slopes of both treatment and controls do not differ

274 from zero across families, this pattern represents a purely environmental response to thiamine

275 treatment. By contrast, one family may respond to thiamine treatment differently than another,

276 and this pattern can result in a family $\mathrm{x}$ treatment interaction. Using this approach, we can

277 disentangle among-family (i.e., putatively adaptive) variation in gene expression from both an

278 additive (purely environmental) response to treatment and a family $\mathrm{x}$ treatment interaction. We

279 calculated regressions separately for each treatment group with $\log ($ hazard ratio) as the

280 explanatory variable and fragments per million mapped fragments (FPM) as the response

281 variable. We again conducted each regression using 1 randomly selected individual from each

282 family and treatment combination and repeated this process 1,000 times per gene. We identified

283 significant differences between the treatment and control groups by comparing the bootstrapped

284 coefficient estimates for slope and intercept. To approximate a significance cut off of $\alpha=0.05$,

285 we identified genes where the mean coefficient estimate $+/-1$ standard error (approximated by

$28683 \%$ quantiles; Payton, Greenstone, \& Schenker, 2003) between the treatment and control groups

287 did not overlap. In addition, slopes were considered to not differ from zero if their 95\%

288 confidence intervals included zero. We also categorized genes according to whether or not the

289 slopes or intercepts of the treated and untreated regression lines differed from one another. 
290

291

292

293

294

295

296

297

298

299

300

301

302

303

304

305

306

307 belonging to family A).

Differential expression analyses: treatment effects

309 Across all 36 individuals sequenced, the average rate of single concordant alignment for read

310 pairs per sample was $80.9 \%$ and $62.2 \%$ of read pairs were successfully assigned to annotated

311 features with featureCounts (Table S1). The final list of a priori genes included 106 unique

312 genes. Of these genes, 17 were differentially expressed between treated and untreated individuals 
313 after controlling for false discovery $\left(p_{\text {adj }}<0.05\right.$; Table 1$)$. Three of these genes-which encode

314 adenylate kinase and reduced folate carrier - are involved in regulating intracellular

315 concentrations of TDP (Fig. S2). Most of the remaining a priori DEGs comprise TDP-dependent

316 enzymes or kinases that control TDP-dependent enzyme activity (Table 1). Differential

317 expression analysis conducted using the full list of assembled transcripts resulted in the

318 identification of 3,616 DEGs after controlling for false discovery ( $p_{\text {adj }}<0.05$; Table S3). A

319 principal component analysis conducted with these DEGs showed treated samples clustering

320 closely together, with PC1 differentiating treated and untreated individuals within each family

321 and describing $59 \%$ of the variation (Fig. 2).

322 Gene co-expression network and gene ontology analyses: treatment effect genes

323 After Bonferroni correction, 3 WGCNA modules of co-expressed genes were significantly

324 correlated with treatment status (corrected $p<0.05$ ). Module A contained 667 genes and these

325 genes were associated with 647 significantly overrepresented GO terms; 46 GO terms were

326 unique to Module A and associated with the top genes in the module when genes were ranked by

327 gene significance (terminal nodes in Fig. 3A, Table S4). Many GO terms associated with genes

328 in Module A were related to neurological function and development, including regulation of

329 long-term neuronal synaptic plasticity, neurotransmitter secretion, and neuromuscular junction

330 development (Fig. 3A). Differential expression of genes involved in neurological function may

331 underlie the abnormal locomotion patterns observed in thiamine deficient fry. Module B

332 contained 355 genes associated with 261 significantly overrepresented GO terms; 17 GO terms

333 were unique to Module B and associated with the top genes in the module. Of these 17 GO

334 terms, 8 were associated with metabolism, including positive regulation of insulin secretion,

335 glutamine metabolic process, and tricarboxylic acid metabolic process (Fig. 3B). Differential 
expression of genes related to these terms is likely related to diminished metabolic rates in

337 untreated individuals. Module C contained 470 genes associated with 768 significantly

overrepresented GO terms; $51 \mathrm{GO}$ terms were unique to Module $\mathrm{C}$ and associated with the top

genes in the module. Many of these GO terms were related to cardiovascular function and

341 (Fig. 3C).

343 learning, retinal metabolic process, adaptation of rhodopsin mediated signaling, and post-

344 embryonic camera-type eye development. Differential expression of genes related to these terms

345 in untreated individuals is likely associated with decreased visual acuity documented in thiamine

346 deficient fry (Carvalho et al., 2009). Each module also contained DEGs identified through

347 differential expression analysis (representing $23.4 \%, 18.3 \%$, and $24.5 \%$ of genes in each module,

348 respectively). The DEGs assigned to module A were downregulated in treated individuals, while

349 the DEGs assigned to modules B and C were upregulated in treated individuals (Fig. S3).

\section{Putatively adaptive genes}

351 Maternal effects may influence among-family variation in survival and gene expression.

352 However, we could not identify any maternal characteristics, including maternal thiamine

353 concentrations, that were associated with survival of untreated offspring. Specifically, maternal

354 size and weight were not correlated with untreated offspring survival rate (standard length: $\mathrm{F}_{1,32}$

$355=0.15, p=0.70$; weight: $\mathrm{F}_{1,31}=0.10, p=0.75$ ), indicating that differences in survival among

356 families is not simply a function of maternal condition (Fig. 4A,B). Furthermore, for the 9

357 families sampled for RNA-seq, no relationship appears to exist between maternal muscle or egg

358 thiamine concentrations and proportion of untreated offspring surviving $(n=8$ and $n=9$, 
respectively; Fig. 4C,D). Results of linear regressions also indicated that egg thiamine concentration was not a significant predictor of $\log ($ hazard ratio $)\left(\mathrm{F}_{1,7}=2.18, p=0.18\right.$; Fig. S4). Although we cannot entirely rule out the influence of maternal effects, these results suggest that maternal effects are not driving all of the among-family variation in survival.

individuals $(\mathrm{n}=18)$ and with family hazard ratio as the explanatory variable yielded 1,656 DEGs. Of these DEGs, 471 were discarded because the adjusted $r^{2}$ of the regressions for these genes were $<0.3$, and an additional 210 were discarded because the regression slopes did not significantly differ from 0 . The remaining 1,446 putatively adaptive DEGs were divided into 812 genes positively associated with increased risk of mortality (Fig. 5A,C) and 634 genes negatively associated with increased risk of mortality (Fig 5B,C; Table S5).

Adaptively expressed DEGs with positive and negative slopes were associated with 870 and 741 overrepresented GO terms, respectively $(p<0.001)$. Of the top 50 terms associated with genes in each slope category, 17 terms were shared between the categories (Table S6). Shared terms were related to a variety of processes, including regulation of transcription, response to glucose, aging, and oxidation-reduction process. Terms associated with genes with negative slopes (i.e., genes upregulated in families with high survival) relate to growth and developmental processes, including cellular proliferation, DNA replication, embryo development, neurogenesis, and visual perception (Table S6). Genes with positive slopes (i.e., genes upregulated in families with low survival) were associated with terms that seems to indicate stressful physiological conditions, including response to hydrogen peroxide, response to hypoxia, response to toxic substance, and several terms related to toll-like receptor signaling pathways (Table S6). 


\section{Additive and treatment $x$ among-family effect genes}

382 The differential expression of 114 genes in response to thiamine treatment was driven entirely by

383 additive effects, meaning that the response to treatment was equal among families (Fig. 6A). Of

384 these 114 genes, 84 genes also showed no among-family variation in gene expression, suggesting

385 that the response to thiamine in this group of genes is entirely environmental (i.e., not genetic).

386 For 30 additively expressed genes, we also identified significant among-family variation in

387 expression, suggesting that these genes are both putatively adaptive and additive (i.e., they

388 respond equally across families) (Fig. 6A,B). For example, expression level of popeye domain-

389 containing protein 2 (popdc2; SI Discussion) decreases with increasing hazard ratio rank for both

390 treatment groups, with equal slopes between treatments (Fig. 6B).

For 597 genes differentially expressed with respect to treatment, the slopes of the

392 regressions for each treatment group differed, indicating a family $\mathrm{x}$ treatment effect. The vast

393 majority (460/720) of family- and treatment-effect genes fell into two categories (Fig. 6A), both

394 of which had a shared y-intercept (see Fig. S5 for all identified categories). Gene expression

395 between treated and untreated individuals was most similar at lower hazard ratio values, with

396 expression levels of treated and untreated individuals diverging with increasing hazard ratio. For

397 example, expression levels of the optineurin and gamma-crystallin M2 genes did not differ

398 between treatments for the family with the highest survival (lowest hazard ratio value) (Fig.

$3996 \mathrm{C}, \mathrm{D})$. These two genes differ in their responses to treatment; thiamine treatment decreases

400 expression of optineurin in low survival families, whereas treatment increases expression of

401 gamma-crystallin M2 in low survival families. Because the slopes of the treatment group

402 regressions differ, treatment does not evenly affect gene expression across families; the families 
403 with the lowest survival (highest hazard ratio values) experienced the largest shifts in expression

404 levels in response to treatment.

\section{Discussion}

406 Among all families and across both years, we found a high degree of variation in survival (Fig.

407 1B) and egg thiamine concentrations, with most females producing eggs that cannot survive

408 without supplemental treatment (Fig. 1C). The ubiquity of low egg thiamine in these samples is

409 consistent with extremely limited reproductive success documented in Lake Champlain

410 tributaries (Prévost, Hill, Grant, Ardren, \& Fraser, in press). Treatment with supplemental

411 thiamine does improve survival outcomes for all families, but does not guarantee survival in

412 families with higher hazard ratios (Fig. S1D-I). Egg thiamine concentration could not predict

413 survival (hazard ratio value) for the 9 families included in gene expression analyses (Fig. S4),

414 and no relationships appear to exist between maternal muscle or egg thiamine concentrations and

415 proportion of untreated offspring surviving (Fig. 4C,D). Across all families, maternal length and

416 weight also do not predict offspring survival (proportion surviving; Fig. 4A,B). Because all

417 offspring were raised in a common environment, the absence of this relationship coupled with

418 the high variation in among-family survival indicates that family identity (i.e., genetic

419 background) plays an important role in determining whether an individual will survive thiamine

420 deficiency. Furthermore, in the face of thiamine deficiency, certain families are better able to

421 maintain gene expression profiles that approximate expression profiles under thiamine-rich

422 conditions without the aid of supplemental thiamine (Fig. 6), consistent with a genetic basis for

423 tolerance to low thiamine availability.

Across all families, we found that a large number of genes responded to supplemental

425 thiamine treatment. Of the genes hypothesized to be differentially expressed between treated and 
426 untreated individuals a priori, two gene products perform functions that balance relative

427 intracellular concentrations of thiamine and its various derivatives (see SI text for Discussion;

428 Fig. S2). From the full list of transcript counts, we identified three modules of co-expressed

429 genes associated with treatment status (Fig. 3). For each of these modules, clear themes emerged

430 from their unique lists of overrepresented GO terms. Module A's association with neurological

431 function and development identified genes related to specific signs of thiamine deficiency in

432 Atlantic salmon fry, such as uncoordinated swimming patterns, inability to maintain an upright

433 position in the water column, and absence of avoidance behavior in response to light exposure

434 (Fisher, Spitsbergen, et al., 1995). These signs of thiamine deficiency may also be related to

435 other overrepresented terms unique to Module A, including responses to stimuli, such as

436 phototaxis and negative chemotaxis. Overrepresented terms in Module B identified genes

437 associated with metabolism, and differential expression of these genes likely underlies slower

438 rates of development under thiamine deficient conditions, with treated individuals achieving

439 larger body sizes than untreated individuals of the same age (Fitzsimons et al., 2009). In Module

$440 \mathrm{C}$, overrepresented terms identified genes related to cardiovascular function and development

441 and may drive vascular dysfunction observed in untreated individuals, as evidenced by

442 hemorrhaging, vascular congestion, and irregular heart rate (Fig. 1A; Fisher, Spitsbergen, et al.,

443 1995). The ubiquity of terms related to vision and eye development shared across all three

444 modules of co-expressed genes demonstrates the complexity of relationships among genes that

445 influence proper development of the visual system (e.g., A: visual learning and phototaxis; B:

446 retinol and retinal metabolic processes; C: post-embryonic camera-type eye development). 
associated with among-family variation in survival. For example, 812 genes are significantly upregulated in untreated individuals from high-survival families (Fig. 5A,C). This result suggests

451 that the increased expression of these genes is associated with higher survival and that these

452 genes, or the various cis or trans acting regulatory elements that influence their expression, could

453 respond to selection in a thiamine-poor environment. Of course, these putatively adaptive genes

454 could also be affected by maternal effects, though survival was not correlated with any maternal

455 or egg traits that we measured (Fig. 4), heritable epigenetic effects (Le Luyer et al., 2017), or

456 other environmental factors. Thus, we are not suggesting that all of these genes would underlie

457 an adaptive response to selection, but rather that this list represents a suite of candidate genes

458 that would likely respond to selection. The fact that there are so many survival-associated genes

459 implicated in an among-family response also suggests that there is sufficient underlying genetic

460 variation in the population to respond to selection. This result, coupled with our survival data,

461 suggest that this population could adaptively respond to selection in the wild. It is worth noting

462 that there is no natural reproduction in Lake Champlain and that all released salmon are treated

463 with supplemental thiamine; this relaxed natural selection could be limiting the successful

464 reintroduction of salmon into the wild.

Of the 3,616 treatment-effect DEGs, 84 displayed evidence of an additive effect of

466 treatment that was not associated with among-family survival (Fig. 6A). In other words, these 84

467 genes responded to thiamine treatment equally across families and represent a consistent

468 environmental response to the treatment condition. The lack of association between among-

469 family variation in survival and the expression of these genes and the fact that these genes

470 changed in expression roughly equally across families suggests that the change in expression due

471 to thiamine is an entirely environmental response. Thus, we would not predict these genes to 
472 respond to selection in a thiamine-poor environment. A small subset of putatively adaptive genes

$473(\mathrm{n}=30)$ exhibited an additive response to treatment across families (i.e., the slopes of the

474 regressions were non-zero but did not differ with respect to treatment) (Fig. 6A,B; SI

475 Discussion). By contrast, 597 DEGs were adaptively expressed and provided evidence of a

476 family $x$ treatment interaction. Most of the genes exhibiting both treatment and family effects

$477(460 / 720$ or $64 \%)$ followed predictable patterns of expression that can be broadly grouped into

478 two out of six identified categories (Fig 6D; see Fig. S5 for all family x treatment patterns). For

479 both categories, expression is most similar between treatments in families with high survival and

480 begins to diverge as survival declines. These results illustrate that treatment can have different

481 effects on different families. The fact that the majority (64\%) of family $\mathrm{x}$ treatment-effect genes

482 occur in the two categories with shared y-intercepts indicates that a successful response to

483 thiamine-poor conditions involves the maintenance of homeostatic conditions.

\section{Conclusion}

485 Across families, we found no relationship between egg thiamine concentration, maternal traits,

486 and the risk of mortality due to thiamine deficiency, indicating that among-family genetic

487 variation plays an important role in determining thiamine deficiency outcomes. Through gene

488 co-expression network analyses, we determined that many GO terms associated with top DEGs

489 are consistent with observed behavioral and physical signs of thiamine deficiency. Specifically,

490 terms related to neurological function and development, metabolism, cardiovascular function,

491 and visual system development parallel signs of deficiency including uncoordinated swimming

492 patterns, stunted growth, irregular heart rate, and decreased visual acuity. We also described two

493 broad categories of gene expression patterns in response to thiamine deficiency: (1) putatively

494 adaptive genes, which underlie family-level differences in tolerance to low thiamine availability 
and represent candidate genes likely to respond to selection, and (2) treatment effect genes, which comprise additive and family $\mathrm{x}$ treatment effect responses to changes in available thiamine. An additive response coupled with no among-family variation in expression identifies genes that are plastic and respond purely as a function of the treatment condition (i.e., different environments). Such genes would be useful to identify in scenarios where a response to selection was not desirable (e.g., captive breeding programs). Family $\mathrm{x}$ treatment effect genes, on the other hand, can be associated with differences in among-family variation in survival, and illustrate that genetic background can differentially affect patterns of gene expression. More importantly, our results identified putatively adaptive genes that would likely respond to selection and that are

504 directly associated with among-family variation in survival. Precisely how much of a response to

505 selection in the wild could occur remains unknown, but uncovering the adaptive genetic variation 506 required for a response to selection represents the first step towards the successful management

507 and conservation species threatened by changing environmental conditions.

\section{Acknowledgements}

509 We thank T. Chairvolotti and K. Kelsey of the Vermont Fish and Wildlife Department for

510 coordination of spawning and gamete collection events. We also thank H. Bouchard, P. Boynton,

511 S. Frost, T. Jones, E. Lehnert, W. Olmstead, N. Staats, and D. Wong of the US Fish and Wildlife

512 Service for coordination of spawning events, disease testing of adult salmon and offspring,

513 collection of mortality data, rearing of offspring, and assistance with all logistical aspects of this

514 study. Additionally, we thank the Purdue Genomics Core for their sequencing efforts, the

515 Rinchard lab at the State University of New York College at Brockport for thiamine

516 concentration analyses, C. Searle for providing code and assistance with survival analyses, and

517 C. Schraidt and M. Sparks for constructive comments and discussion. This research was funded 
bioRxiv preprint doi: https://doi.org/10.1101/731497; this version posted August 10, 2019. The copyright holder for this preprint (which was not certified by peer review) is the author/funder, who has granted bioRxiv a license to display the preprint in perpetuity. It is made available under aCC-BY-NC-ND 4.0 International license.

518 by the Alton A. Lindsey Graduate Fellowship in Ecology (Purdue University) awarded to AMH

519 and from support from the Purdue Department of Biological Sciences to MRC. The findings and

520 conclusions in the article are those of the authors and do not necessarily represent the views of

521 the U.S. Fish and Wildlife Service. 


\section{References}

Alexa, A., Rahnenfuhrer, J., \& Lengauer, T. (2006). Improved scoring of functional groups from gene expression data by decorrelating GO graph structure. Bioinformatics, 22(13), 16001607. doi: 10.1093/bioinformatics/btl140

Alexa, Adrian, \& Rahnenfuhrer, J. (2016). topGO: Enrichment analysis for gene ontology (Version R package v2.30.1).

Balk, L., Hägerroth, P.-Å., Åkerman, G., Hanson, M., Tjärnlund, U., Hansson, T., ... Sundberg, H. (2009). Wild birds of declining European species are dying from a thiamine deficiency syndrome. Proceedings of the National Academy of Sciences, 106(29), 12001-12006.

Balk, L., Hägerroth, P.-Å., Gustavsson, H., Sigg, L., Åkerman, G., Ruiz Muñoz, Y., ... Hansson, T. (2016). Widespread episodic thiamine deficiency in Northern Hemisphere wildlife. Scientific Reports, 6, 38821.

Bernatchez, L. (2016). On the maintenance of genetic variation and adaptation to environmental change: Considerations from population genomics in fishes. Journal of Fish Biology, 89(6), 2519-2556. doi: 10.1111/jfb.13145

Bettendorff, L. (2013). Thiamine. In Handbook of Vitamins, Fifth Edition (pp. 267-324). CRC Press.

Bolger, A. M., Lohse, M., \& Usadel, B. (2014). Trimmomatic: A flexible trimmer for Illumina sequence data. Bioinformatics, 30(15), 2114-2120. doi: 10.1093/bioinformatics/btu170

Brown, S. B., Honeyfield, D. C., Hnath, J. G., Wolgamood, M., Marcquenski, S. V., Fitzsimons, J. D., \& Tillitt, D. E. (2005). Thiamine status in adult salmonines in the Great Lakes. Journal of Aquatic Animal Health, 17(1), 59-64.

Butterworth, R. F. (2009). Thiamine deficiency-related brain dysfunction in chronic liver failure. Metabolic Brain Disease, 24(1), 189-196. doi: 10.1007/s11011-008-9129-y

Carvalho, P. S. M., Tillitt, D. E., Zajicek, J. L., Claunch, R. A., Honeyfield, D. C., Fitzsimons, J. D., \& Brown, S. B. (2009). Thiamine deficiency effects on the vision and foraging ability of lake trout fry. Journal of Aquatic Animal Health, 21(4), 315-325.

Christie, M. R., Marine, M. L., Fox, S. E., French, R. A., \& Blouin, M. S. (2016). A single generation of domestication heritably alters the expression of hundreds of genes. Nature Communications, 7, 10676. doi: 10.1038/ncomms 10676

Cox, D. R. (1972). Regression models and life tables. Journal of the Royal Statistical Society. Series B (Methodological), 34, 187-220.

Essa, E., Velez, M. R., Smith, S., Giri, S., Raman, S. V., \& Gumina, R. J. (2011). Cardiovascular magnetic resonance in wet beriberi. Journal of Cardiovascular Magnetic Resonance, 13(1), 41. doi: 10.1186/1532-429X-13-41

Fisher, J. P., Spitsbergen, J. M., Iamonte, T., Little, E. E., \& Delonay, A. (1995). Pathological and behavioral manifestations of the "Cayuga syndrome," a thiamine deficiency in larval landlocked Atlantic salmon. Journal of Aquatic Animal Health, 7(4), 269-283.

Fisher, J. P., Spitzbergen, J. M., Getchell, R., Symula, J., Skea, J., Babenzein, M., \& Chiotti, T. (1995). Reproductive failure of landlocked Atlantic Salmon from New York's Finger Lakes: Investigations into the etiology and epidemiology of the "Cayuga Syndrome." Journal of Aquatic Animal Health, 7, 81-94.

Fitzsimons, J. D., Brown, S. B., Honeyfield, D. C., \& Hnath, J. G. (1999). A review of early mortality syndrome (EMS) in Great Lakes salmonids: Relationship with thiamine deficiency. Ambio, 28, 9-15. 
Fitzsimons, J. D., Brown, S. B., Williston, B., Williston, G., Brown, L. R., Moore, K., ... Tillitt, D. E. (2009). Influence of thiamine deficiency on lake trout larval growth, foraging, and predator avoidance. Journal of Aquatic Animal Health, 21(4), 302-314.

Fitzsimons, J. D., Williston, B., Amcoff, P., Balk, L., Pecor, C., Ketola, H. G., ... Honeyfield, D. C. (2005). The effect of thiamine injection on upstream migration, survival, and thiamine status of putative thiamine-deficient coho salmon. Journal of Aquatic Animal Health, $17(1), 48-58$.

Foster, Z. S. L., Sharpton, T. J., \& Grünwald, N. J. (2017). Metacoder: An R package for visualization and manipulation of community taxonomic diversity data. PLOS Computational Biology, 15.

Franks, S. J., Kane, N. C., O’Hara, N. B., Tittes, S., \& Rest, J. S. (2016). Rapid genome-wide evolution in Brassica rapa populations following drought revealed by sequencing of ancestral and descendant gene pools. Molecular Ecology. doi: 10.1111/mec.13615

Futia, M. H., Hallenbeck, S., Noyes, A. D., Honeyfield, D. C., Eckerlin, G. E., \& Rinchard, J. (2017). Thiamine deficiency and the effectiveness of thiamine treatments through broodstock injections and egg immersion on Lake Ontario steelhead trout. Journal of Great Lakes Research, 43(2), 352-358.

Hansson, S., Karlsson, L., Ikonen, E., Christensen, O., Mitans, A., Uzars, D., ... Ragnarsson, B. (2001). Stomach analyses of Baltic salmon from 1959 -1962 and 1994 -1997: Possible relations between diet and yolk-sac-fry mortality (M74). Journal of Fish Biology, 58(6), $1730-1745$.

Harder, A. M., Ardren, W. R., Evans, A. N., Futia, M. H., Kraft, C. E., Marsden, J. E., ... Christie, M. R. (2018). Thiamine deficiency in fishes: Causes, consequences, and potential solutions. Reviews in Fish Biology and Fisheries, 28(4), 865-886. doi: 10.1007/s11160-018-9538-x

Honeyfield, D. C., Ross, J. P., Carbonneau, D. A., Terrell, S. P., Woodward, A. R., Schoeb, T. R., ... Hinterkopf, J. P. (2008a). Pathology, physiologic parameters, tissue contaminants, and tissue thiamine in morbid and healthy central Florida adult American alligators. J.Wildl.Dis., 44(2), 280-294.

Honeyfield, D. C., Ross, J. P., Carbonneau, D. A., Terrell, S. P., Woodward, A. R., Schoeb, T. R., ... Hinterkopf, J. P. (2008b). Pathology, physiologic parameters, tissue contaminants, and tissue thiamine in morbid and healthy central Florida adult American alligators (Alligator mississippiensis). Journal of Wildlife Diseases, 44(2), 280-294. doi: 10.7589/0090-3558-44.2.280

Houde, A. L. S., Saez, P. J., Wilson, C. C., Bureau, D. P., \& Neff, B. D. (2015). Effects of feeding high dietary thiaminase to sub-adult Atlantic salmon from three populations. Journal of Great Lakes Research, 41, 898-906.

Keinänen, M., Uddström, A., Mikkonen, J., Casini, M., Pönni, J., Myllylä, T., ... Vuorinen, P. J. (2012). The thiamine deficiency syndrome M74, a reproductive disorder of Atlantic salmon (Salmo salar) feeding in the Baltic Sea, is related to the fat and thiamine content of prey fish. ICES Journal of Marine Science, 69(4), 516-528.

Ketola, H. G., Bowser, P. R., Wooster, G. A., Wedge, L. R., \& Hurst, S. S. (2000). Effects of thiamine on reproduction of Atlantic salmon and a new hypothesis for their extirpation in Lake Ontario. Transactions of the American Fisheries Society, 129(2), 607-612.

Kim, D., Langmead, B., \& Salzberg, S. L. (2015). HISAT: A fast spliced aligner with low memory requirements. Nature Methods, 12(4), 357-360. doi: 10.1038/nmeth.3317 
Kleinbaum, D. G., \& Klein, M. (2012). Survival analysis: A self-learning text (3rd ed). New York: Springer.

Langfelder, P., \& Horvath, S. (2008). WGCNA: An R package for weighted correlation network analysis. BMC Bioinformatics, 9(1), 559. doi: 10.1186/1471-2105-9-559

Le Luyer, J., Laporte, M., Beacham, T. D., Kaukinen, K. H., Withler, R. E., Leong, J. S., ... Bernatchez, L. (2017). Parallel epigenetic modifications induced by hatchery rearing in a Pacific salmon. Proceedings of the National Academy of Sciences, 114(49), 1296412969. doi: 10.1073/pnas.1711229114

Lee, B.-J., Jaroszewska, M., Dabrowski, K., Czesny, S., \& Rinchard, J. (2009). Effects of vitamin $\mathrm{B}_{1}$ (thiamine) deficiency in lake trout alevins and preventive treatments. Journal of Aquatic Animal Health, 21(4), 290-301.

Liao, Y., Smyth, G. K., \& Shi, W. (2014). featureCounts: an efficient general purpose program for assigning sequence reads to genomic features. Bioinformatics, 30(7), 923-930. doi: 10.1093/bioinformatics/btt656

Lien, S., Koop, B. F., Sandve, S. R., Miller, J. R., Kent, M. P., Nome, T., ... Davidson, W. S. (2016). The Atlantic salmon genome provides insights into rediploidization. Nature. doi: 10.1038/nature17164

Love, M. I., Huber, W., \& Anders, S. (2014). Moderated estimation of fold change and dispersion for RNA-seq data with DESeq2. Genome Biology, 15(12), 550. doi: 10.1186/s 13059-014-0550-8

Marsden, J. E., \& Langdon, R. W. (2012). The history and future of Lake Champlain's fishes and fisheries. Journal of Great Lakes Research, 38, 19-34. doi: 10.1016/j.jglr.2011.09.007

Marshall, D. J., Heppell, S. S., Munch, S. B., \& Warner, R. R. (2010). The relationship between maternal phenotype and offspring quality: Do older mothers really produce the best offspring? Ecology, 91(10), 2862-2873. doi: 10.1890/09-0156.1

Mörner, T., Hansson, T., Carlsson, L., Berg, A.-L., Ruiz Muñoz, Y., Gustavsson, H., ... Balk, L. (2017). Thiamine deficiency impairs common eider (Somateria mollissima) reproduction in the field. Scientific Reports, 7(1). doi: 10.1038/s41598-017-13884-1

Myers, J. H., Simberloff, D., Kuris, A. M., \& Carey, J. R. (2000). Eradication revisited: Dealing with exotic species. Trends in Ecology \& Evolution, 15(8), 316-320. doi: 10.1016/S01695347(00)01914-5

Passow, C. N., Henpita, C., Shaw, J. H., Quackenbush, C. R., Warren, W. C., Schartl, M., ... Tobler, M. (2017). The roles of plasticity and evolutionary change in shaping gene expression variation in natural populations of extremophile fish. Molecular Ecology, 26(22), 6384-6399. doi: 10.1111/mec. 14360

Payton, M. E., Greenstone, M. H., \& Schenker, N. (2003). Overlapping confidence intervals or standard error intervals: What do they mean in terms of statistical significance? Journal of Insect Science, 3, 1-6.

Pertea, M., Pertea, G. M., Antonescu, C. M., Chang, T.-C., Mendell, J. T., \& Salzberg, S. L. (2015). StringTie enables improved reconstruction of a transcriptome from RNA-seq reads. Nature Biotechnology, 33(3), 290-295. doi: 10.1038/nbt.3122

Prévost, A., Hill, N., Grant, J., Ardren, W., \& Fraser, D. (in press). Patterns of reproductive success among reintroduced Atlantic salmon in two Lake Champlain tributaries. Conservation Genetics, in press. 
Pritchard, J. K., Pickrell, J. K., \& Coop, G. (2010). The genetics of human adaptation: Hard sweeps, soft sweeps, and polygenic adaptation. Current Biology, 20(4), R208-R215. doi: 10.1016/j.cub.2009.11.055

R Core Team. (2019). R: A language and environment for statistical computing. Retrieved from https://www.R-project.org/

Ritz, C., Baty, F., Streibig, J. C., \& Gerhard, D. (2015). Dose-response analysis using R. PLOS ONE, 10(12), e0146021. doi: 10.1371/journal.pone.0146021

Ross, J. P., Honeyfield, D. C., Brown, S. B., Brown, L. R., Waddle, A. R., Welker, M. E., \& Schoeb, T. R. (2009). Gizzard shad thiaminase activity and its effect on the thiamine status of captive American alligators Alligator mississippiensis. Journal of Aquatic Animal Health, 21(4), 239-248. doi: 10.1577/H08-002.1

Samy, J. K. A., Mulugeta, T. D., Nome, T., Sandve, S. R., Grammes, F., Kent, M. P., ... Våge, D. I. (2017). SalmoBase: An integrated molecular data resource for salmonid species. BMC Genomics, 18(1). doi: 10.1186/s12864-017-3877-1

Sechi, G., \& Serra, A. (2007). Wernicke's encephalopathy: New clinical settings and recent advances in diagnosis and management. The Lancet Neurology, 6(5), 442-455.

Stockwell, C. A., Hendry, A. P., \& Kinnison, M. T. (2003). Contemporary evolution meets conservation biology. Trends in Ecology \& Evolution, 18(2), 94-101.

Therneau, T. (2015). A package for survival analysis in R (Version 2.38). Retrieved from https://CRAN.R-project.org/package=survival

Uusi-Heikkilä, S., Sävilammi, T., Leder, E., Arlinghaus, R., \& Primmer, C. R. (2017). Rapid, broad-scale gene expression evolution in experimentally harvested fish populations. Molecular Ecology. doi: 10.1111/mec.14179

van't Hof, A. E., Campagne, P., Rigden, D. J., Yung, C. J., Lingley, J., Quail, M. A., ... Saccheri, I. J. (2016). The industrial melanism mutation in British peppered moths is a transposable element. Nature, 534(7605), 102-105. doi: 10.1038/nature17951

Wellenreuther, M., \& Hansson, B. (2016). Detecting polygenic evolution: Problems, pitfalls, and promises. Trends in Genetics, 32(3), 155-164. doi: 10.1016/j.tig.2015.12.004

Willoughby, J. R., Harder, A. M., Tennessen, J. A., Scribner, K. T., \& Christie, M. R. (2018). Rapid genetic adaptation to a novel environment despite a genome-wide reduction in genetic diversity. Molecular Ecology, 27(20), 4041-4051. doi: 10.1111/mec.14726

\section{Data Accessibility Statement}

Upon acceptance, code and scripts will be made available at https://github.com/ChristieLab, and aligned reads (Table S1) will be made available via NCBI Sequence Read Archive with accession numbers provided.

\section{Author Contributions}

AMH, WRA, and MRC designed the project. AMH and WRA collected gametes. AMH

performed molecular work. AMH and JRW analyzed data. AMH and MRC wrote the paper. All 
bioRxiv preprint doi: https://doi.org/10.1101/731497; this version posted August 10,2019 . The copyright holder for this preprint (which was not certified by peer review) is the author/funder, who has granted bioRxiv a license to display the preprint in perpetuity. It is made available under aCC-BY-NC-ND 4.0 International license.

695 authors read and approved the final manuscript. 
Table 1. Genes identified as differentially expressed that were hypothesized a priori to be implicated in thiamine deficiency. Gene symbols correspond to those used in S. salar NCBI assembly GCA_000233375.4 (Lien et al., 2016). Direction of log2 fold change values indicate direction of regulation in the treated group relative to the untreated group. Genes without chromosome arm information are located on unplaced scaffolds in the $S$. salar reference assembly.

\begin{tabular}{|c|c|c|c|c|}
\hline Gene symbol & Gene description & $\begin{array}{l}\text { Chromosome } \\
\text { arm }\end{array}$ & $\begin{array}{l}\text { Log } 2 \text { fold } \\
\text { change }\end{array}$ & $\begin{array}{l}\text { FDR corrected } \\
p \text {-value }\end{array}$ \\
\hline bckdha & branched chain keto acid dehydrogenase E1, alpha polypeptide & $9 \mathrm{qc}$ & -0.166 & $1.17 \mathrm{E}-08$ \\
\hline LOC 106600850 & pyruvate dehydrogenase (acetyl-transferring) kinase isozyme 2, mitochondrial-like & $3 q$ & 0.476 & $6.09 \mathrm{E}-05$ \\
\hline kad & adenylate kinase $1-2$ & $1 \mathrm{qb}$ & 0.185 & $6.44 \mathrm{E}-04$ \\
\hline $\mathrm{kad}$ & adenylate kinase & $11 q b$ & 0.235 & $1.70 \mathrm{E}-03$ \\
\hline ilvbl & ilvB (bacterial acetolactate synthase)-like & $20 q b$ & 0.165 & $1.70 \mathrm{E}-03$ \\
\hline LOC106581299 & alkaline phosphatase, tissue-nonspecific isozyme-like & $20 q b$ & 0.638 & $1.70 \mathrm{E}-03$ \\
\hline LOC106583968 & DET1- and DDB1-associated protein 1-like & 23 & 0.260 & $1.70 \mathrm{E}-03$ \\
\hline LOC106569142 & 2-oxoglutarate dehydrogenase, mitochondrial-like & $1 \mathrm{qb}$ & -0.268 & $3.44 \mathrm{E}-03$ \\
\hline LOC106561658 & probable 2-oxoglutarate dehydrogenase E1 component DHKTD1, mitochondrial & $10 q b$ & -0.288 & $1.63 \mathrm{E}-02$ \\
\hline LOC106587025 & 2-oxoglutarate dehydrogenase, mitochondrial & 26 & -0.226 & $1.63 \mathrm{E}-02$ \\
\hline hacl1 & 2-hydroxyacyl-CoA lyase 1 & -- & 0.241 & $2.20 \mathrm{E}-02$ \\
\hline LOC106579320 & pyruvate dehydrogenase (acetyl-transferring) kinase isozyme 2 , mitochondrial-like & $19 q b$ & -0.489 & $2.20 \mathrm{E}-02$ \\
\hline LOC106578452 & pyruvate dehydrogenase (acetyl-transferring) kinase isozyme 3, mitochondrial & $19 \mathrm{qa}$ & -0.214 & $2.28 \mathrm{E}-02$ \\
\hline LOC106580908 & thiamine transporter 2-like & $20 q b$ & 0.969 & 2.28E-02 \\
\hline LOC106560358 & thiamine transporter 2-like & $10 \mathrm{qa}$ & 1.862 & $2.85 \mathrm{E}-02$ \\
\hline LOC 106563967 & $\begin{array}{l}\text { dihydrolipoyllysine-residue acetyltransferase component of pyruvate } \\
\text { dehydrogenase complex, mitochondrial-like }\end{array}$ & $11 q b$ & -0.182 & $3.93 \mathrm{E}-02$ \\
\hline LOC 106575607 & folate transporter 1-like & $17 q a$ & 0.253 & 4.36E-02 \\
\hline
\end{tabular}




\section{Figure Legends}

Figure 1. A) Atlantic salmon fry exhibiting characteristic signs of thiamine deficiency, including hemorrhaging (indicated by arrows) and edema in the posterior portion of the yolk sac. B) Proportion of untreated fry surviving to the onset of exogenous feeding for 35 families spawned in 2016 and 2017. C) Dose-response curve illustrating the relationship between total egg thiamine concentration (nmol/g) and proportion of untreated fry surviving to yolk sac absorption. Shaded grey areas highlight families with egg [thiamine] $<\mathrm{EC}_{25}$ (dark grey) and with egg [thiamine] $>\mathrm{EC}_{25}$ but $<\mathrm{EC}_{50}$ (light grey), where $\mathrm{EC}_{25}$ and $\mathrm{EC}_{50}$ equal the effective concentrations required for $25 \%$ and $50 \%$ survival, respectively .

Figure 2. Principal component analysis performed using differentially expressed genes $(\mathrm{n}=$ 3,616). Results are presented by family (A-I), such that the four colored points plotted in each panel are full siblings. PC1 explains 59\% of the variation and distinguishes among treated and untreated samples. Triangles represent treated individuals and circles represented untreated individuals. Insets are Kaplan-Meier survival distributions for treated (yellow) and untreated (red) individuals from each family. Inset $x$-axes represent time in days post fertilization, whereas the $y$-axes represent survival probability. Hatch marks on survival distributions indicate censored individuals (i.e., samples removed for RNAseq sampling or disease testing). Stand-alone survival distributions are presented in Fig. S1 along with family thiamine concentrations and hazard ratio values.

Figure 3. Gene ontology (GO) hierarchy networks constructed using the metacoder package in $\mathrm{R}$ for three modules (A, B, and C) of co-expressed genes significantly associated with treatment status. Included GO terms were unique to each module and were associated with at least one of the top 20 genes in that module when genes were ranked by WGCNA gene significance. Branch and node colors indicate the biological process child term to which distal nodes belong, with the central grey node representing the biological process level of the GO hierarchy. Terms associated with numbered terminal nodes are provided in Table S4. Terminal nodes marked with an * indicate nodes related to a function or process commonly represented in that module network (e.g., several terminal nodes in Module A are related to neurological function and development).

Figure 4. No associations were found between maternal characteristics (weight $(\mathrm{kg})$ and standard length $(\mathrm{cm})$, respectively) and proportion of untreated offspring surviving at the end of the experiment, when tested with linear regressions (A,B). There also does not appear to be any relationship between maternal muscle or egg thiamine concentrations (nmol/g) and proportion of offspring surviving for the 9 families sample for RNA-seq (C,D). In A-D, families sampled for RNA-seq are indicated by blue points; note that data were unavailable for some families in panels A-C (i.e., 1 family from panels $\mathrm{A}$ and $\mathrm{C}$ and 2 families from panel $\mathrm{B}$ ).

Figure 5. Relative expression of A) glutathione peroxidase (LOC106583190) and B) ATPsensitive inward rectifier potassium channel 12 (LOC106600689) in fragments per million mapped (FPM) across $\log ($ hazard ratio) values. C) The number of putatively adaptive genes 
735 positively and negatively associated with increasing risk of mortality. Putatively adaptive genes 736 positively associated with increasing risk of mortality are largely associated with gene ontology 737 terms related to physiological stress, whereas genes negatively associated with risk are 738 associated with terms related to growth and developmental processes (see Table S6).

739 Figure 6. A) The number of genes differentially expressed in response to treatment and among740 family differences in 4 categories (from left to right): 1) regression slopes are equal between 741 treatment groups and expression is equal across families, indicating a purely environmental 742 effect of treatment on differential gene expression; 2) regression slopes are equal, indicating that 743 families respond evenly to treatment, but among-family differences suggest putatively adaptive 744 responses; 3) and 4) expression levels are equal between treatment groups in high-surviving 745 families with expression patterns diverging in low-surviving families, indicating putatively 746 adaptive responses. Grey lines in example plots in (A) may represent regression lines for either 747 treated or untreated individuals. B-D) Genes exhibiting expression patterns represented in (A). 748 Axes colors correspond to bar colors in (A). Relative expression of B) popeye domain-containing 749 protein 2 (popdc2), C) optineurin (optn), and D) gamma-crystallin M2 (LOC106575874) in 750 fragments per million mapped (FPM) across log(hazard ratio) values. 
bioRxiv preprint doi: https://doi.org/10.1101/731497; this version posted August 10, 2019. The copyright holder for this preprint (which was not certified by peer review) is the author/funder, who has granted bioRxiv a license to display the preprint in perpetuity. It is made available under Figure 1. aCC-BY-NC-ND 4.0 International license.

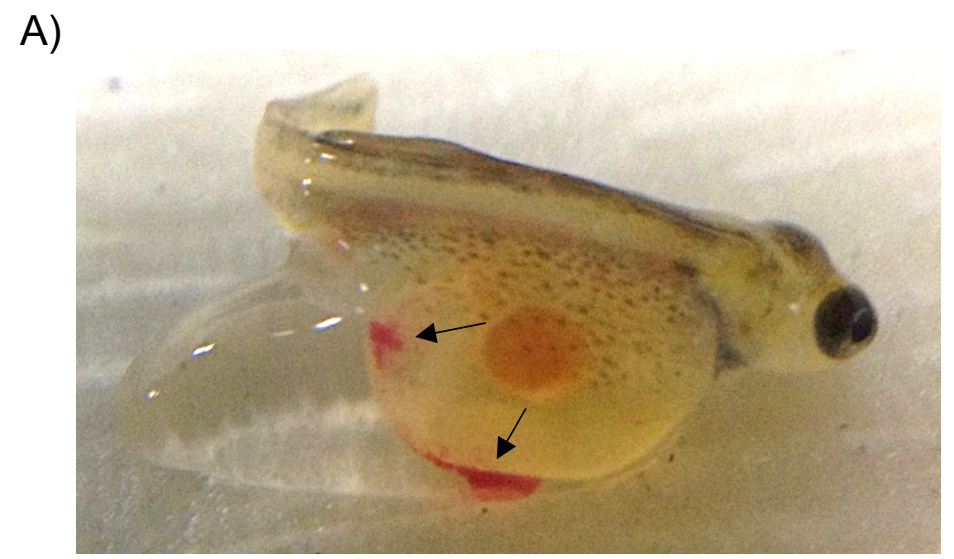

B)
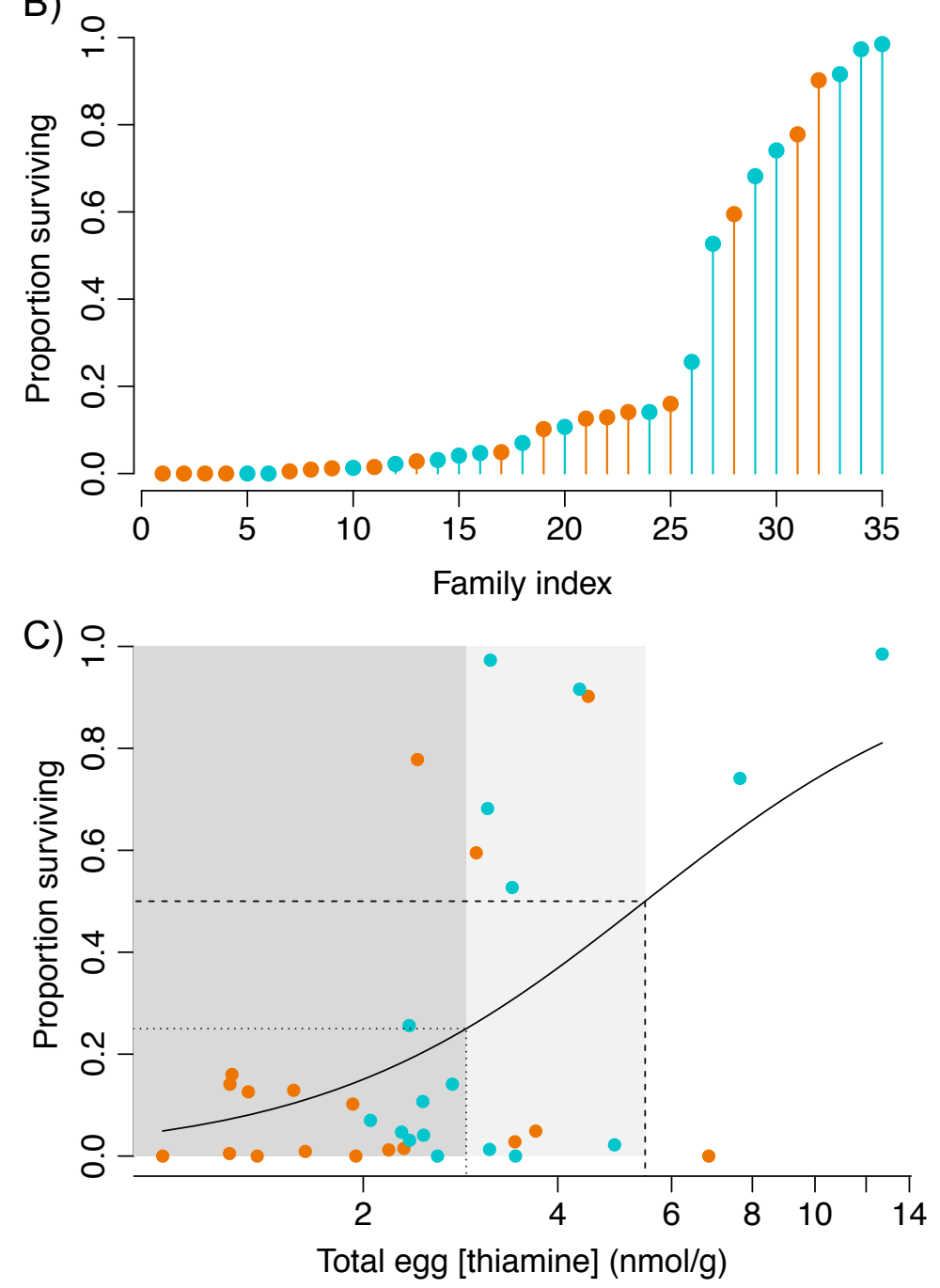

\begin{tabular}{|c|c|c|c|c|}
\hline • & $\begin{array}{l}2016 \\
2017\end{array}$ & - & Logistic curve & $\mathrm{EC}_{25}$ \\
\hline
\end{tabular}


Figure 2.
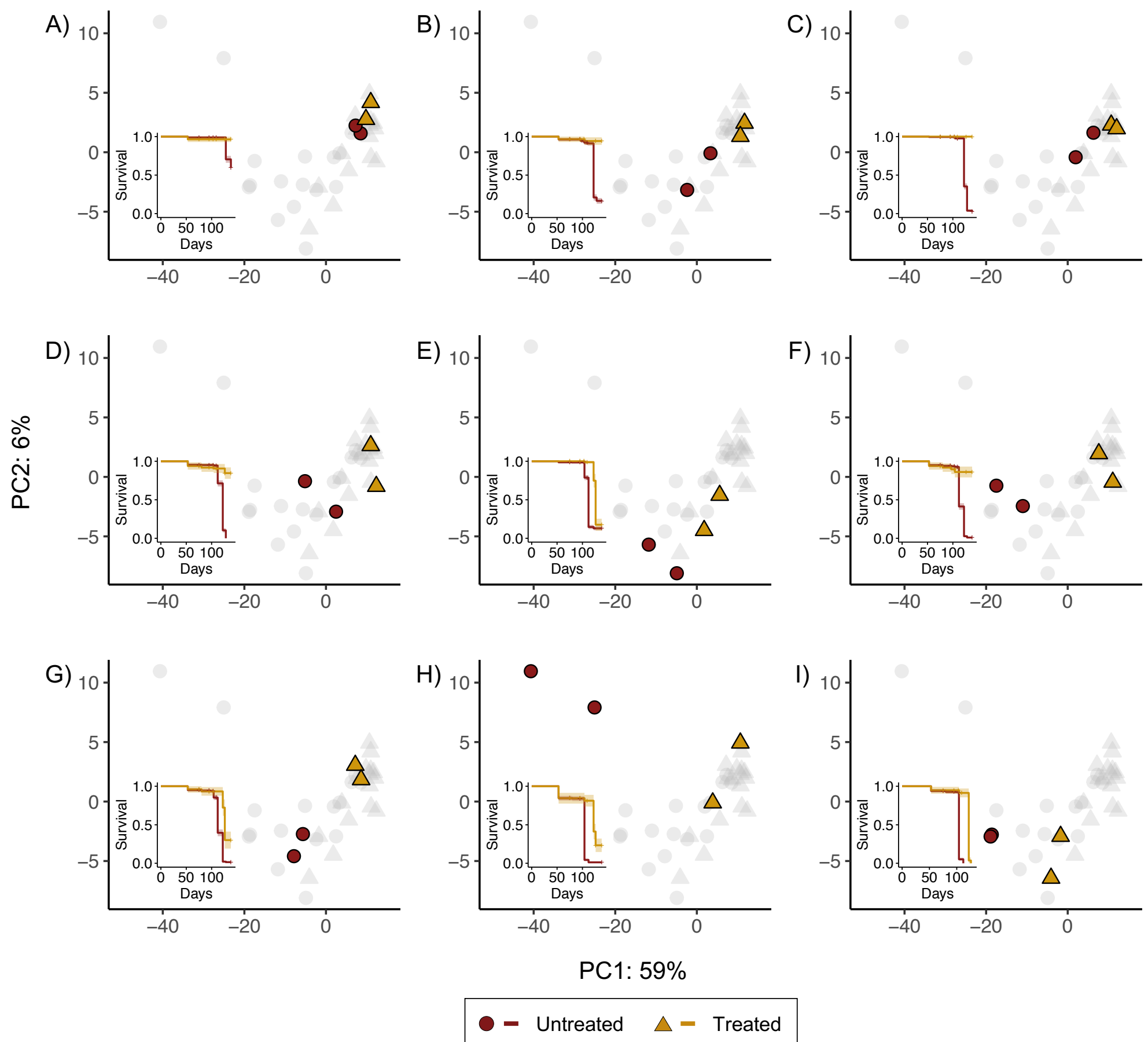
bioRxiv preprint doi: https://doi.org/10.1101/731497; this version posted August 10,2019 . The copyright holder for this preprint (which was not certified by peer review) is the author/funder, who has granted bioRxiv a license to display the preprint in perpetuity. It is made available under

Figure 3. aCC-BY-NC-ND 4.0 International license.
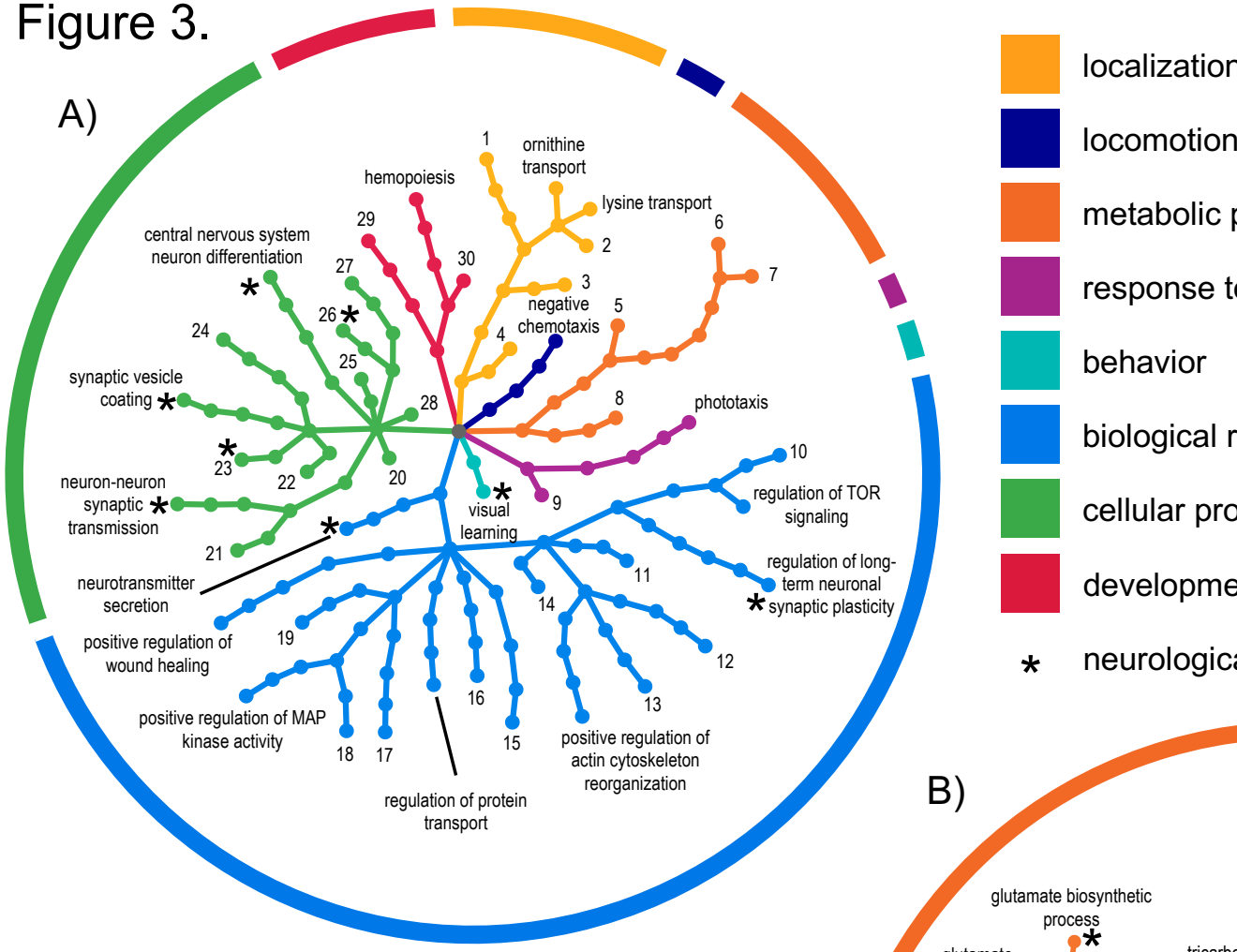

locomotion

metabolic process

response to stimulus

behavior

biological regulation

cellular process

developmental process

* neurological function and development

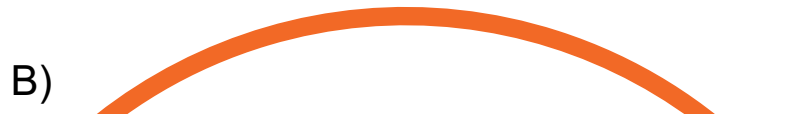

metabolic process

response to stimulus

biological regulation

cellular process

developmental process

* metabolism

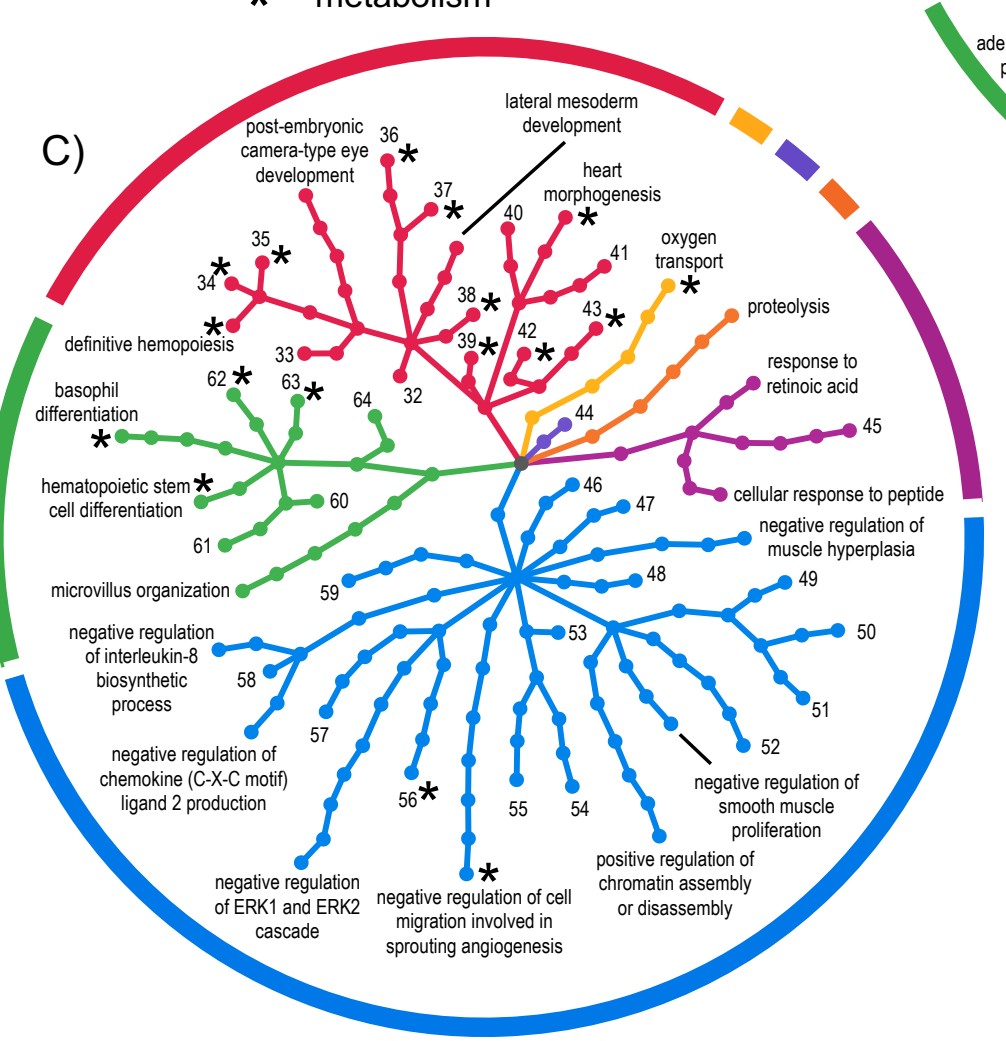

developmental process

localization

multicellular organismal process

metabolic process

response to stimulus

biological regulation

cellular process

* cardiovascular system function and development 
bioRxiv preprint doi: https://doi org/10.1101/731497; this version posted August 10, 2019. The copyright holder for this preprint (which was not certified by peer review) is the author/funder, who has granted bioRxiv a license to display the preprint in perpetuity. It is made available under aCC-BY-NC-ND 4.0 International license.

Figure 4.
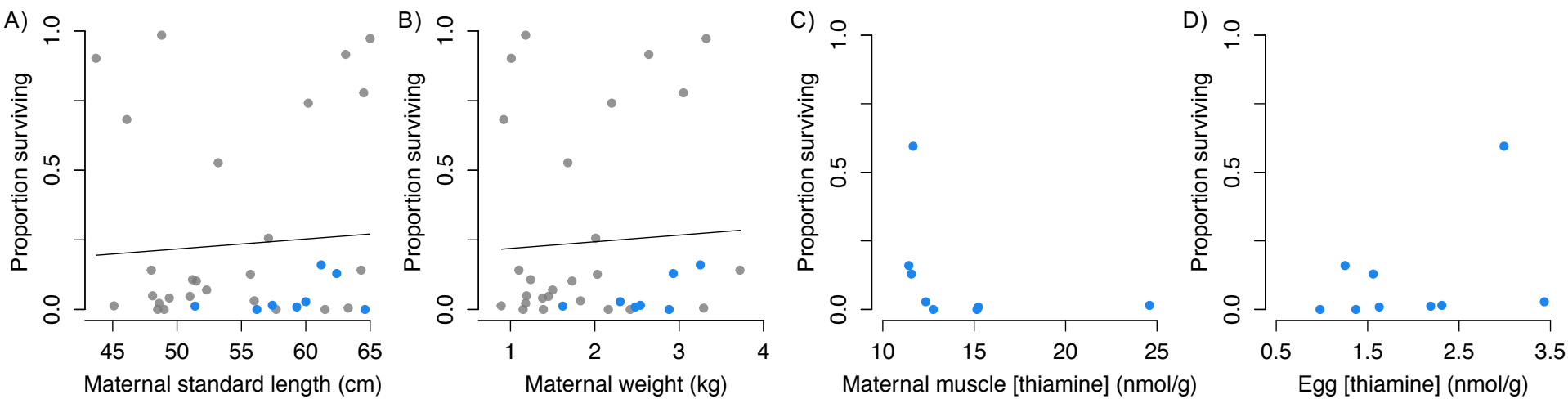


\section{Figure 5.}
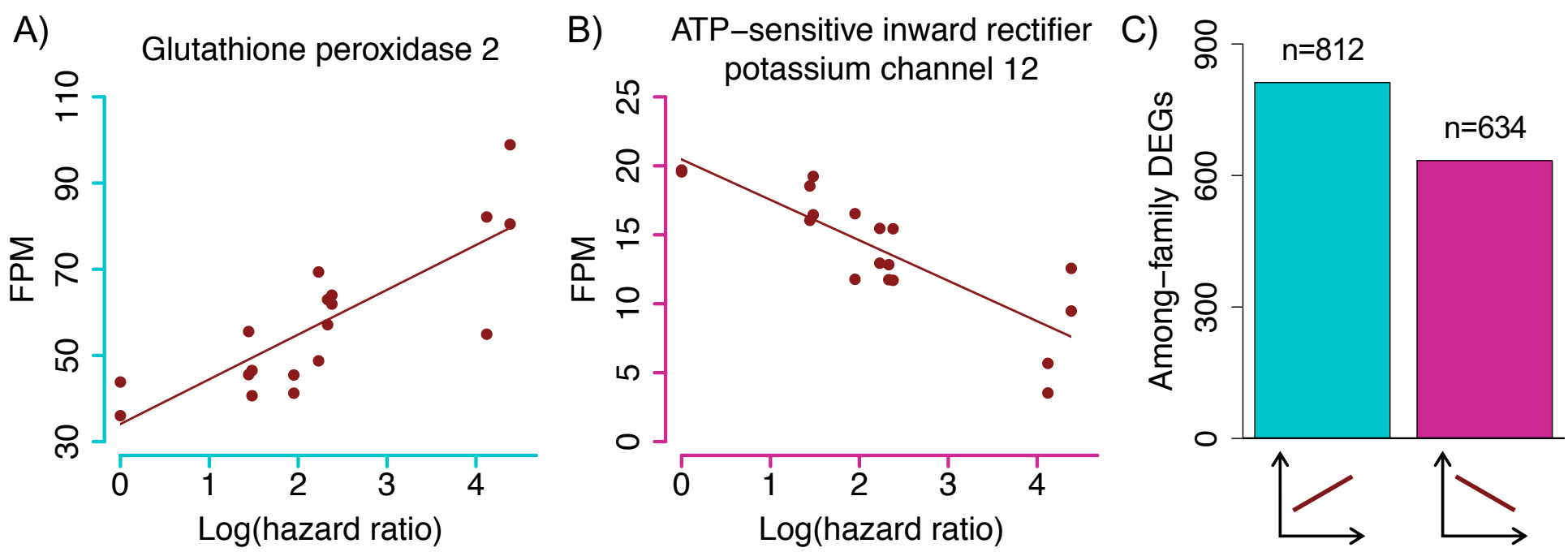
Figure 6.
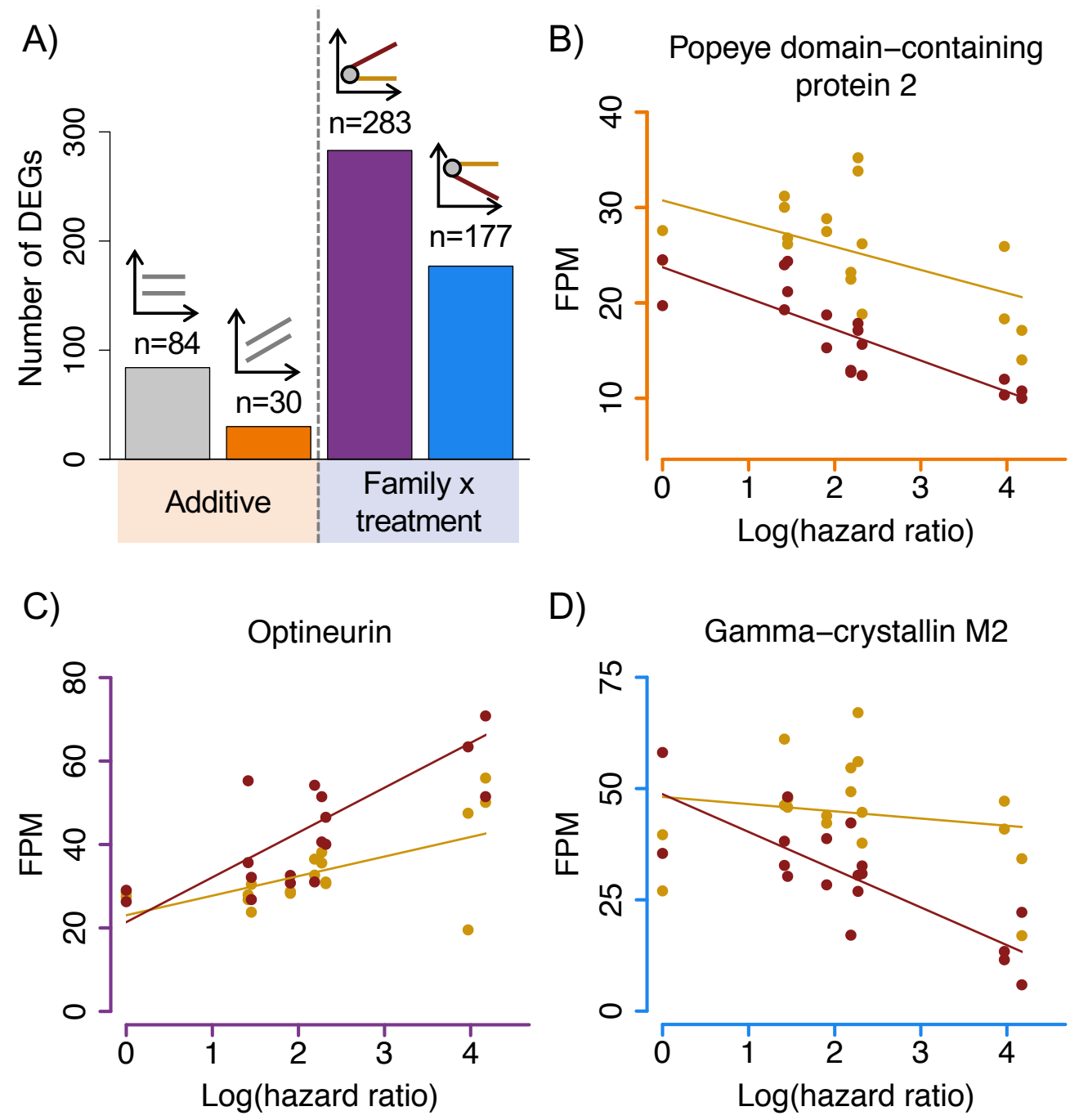
- Untreated
- Treated
○ Y-intercepts do not differ 